\title{
Pedestrian Safety at Rail Grade Crossings: Focus Areas for Research and Intervention
}

\author{
Paul Metaxatos $^{1}$ - P. S. Sriraj ${ }^{1}$
}

Received: 16 October 2015/Revised: 30 December 2015/Accepted: 3 January 2016/Published online: 27 January 2016

(C) The Author(s) 2016. This article is published with open access at Springerlink.com

\begin{abstract}
Contrary to the declining number of fatalities due to train-vehicle collisions at highway-rail grade crossings, the number of pedestrian and bicycle fatalities at highway- and pathway-rail grade crossings has increased in the last dozen years. While engineering solutions and education and enforcements initiatives have been proposed and implemented, little is known as to their effectiveness to mitigate such incidents. This paper reports on findings from the literature and discussions with professionals in the public and private sectors involved in safety at rail grade crossings. Major areas found in need for improvement include (a) advancing consistent standards for warning devices and treatments; (b) advancing consistent approaches for managing non-motorist risk; and (c) continuing commitment to education, engineering, enforcement, and evaluation efforts by enabling stakeholders to provide adequate resources. The paper highlights the multitude of factors related to pedestrian safety in this context, and provides an informed discussion for researchers and practitioners involved in advancing safety initiatives.
\end{abstract}

Keywords Pedestrian safety $\cdot$ Rail grade crossings $\cdot$ State of practice $\cdot$ Expert opinion

Paul Metaxatos

pavlos@uic.edu

1 Urban Transportation Center, University of Illinois at Chicago (M/C 357), 412 South Peoria Street, Suite 340, Chicago, IL 60607, USA

Editor: Xuesong Zhou

\section{Introduction}

In the United States, contrary to the declining number of fatalities due to train-vehicle collisions at highway-rail grade crossings, the number of non-motorist fatalities at rail grade crossings has increased. Indeed, between 2003 and 2014, incidents at highway-rail grade crossings declined $49 \%$ (Fig. 1). However, in the same period, the number of pedestrian fatalities has increased $48 \%$ (Fig. 1).

Advancing pedestrian safety at rail grade crossings is a challenging issue for many reasons. Pedestrian crossing incidents occur in different settings requiring the coordination of different stakeholders with context-sensitive solutions. For example, incidents involving violations at rail grade crossings are different from trespassing incidents away from such crossings. Note that violations in this context can occur in three occasions [33, p. 28]: (a) when a pedestrian enters the crossing when the warning lights are flashing but before the gate arms have begun to move; (b) when a pedestrian enters the crossing when the gate arms are in motion, either in their descent (before train arrival) or ascent (after train departure); and, (c) when a pedestrian enters the crossing after the gate arms are in their horizontal position. On the other hand, trespassing incidents involve individuals who are trespassing on railroad rights-of-way at locations other than authorized grade crossings, including overhead and underground crossings.

Other contextual distinctions regarding pedestrian crossing incidents may include those at crossings that are exclusively used by non-motorists in the vicinity of or within the area of commuter rail stations vis-à-vis those occurring at highwayrail grade crossings with attached sidewalks. Furthermore, incidents in crossings with commuter rail or light rail would require different countermeasures than those occurring in crossings with freight rail. A further complication to 


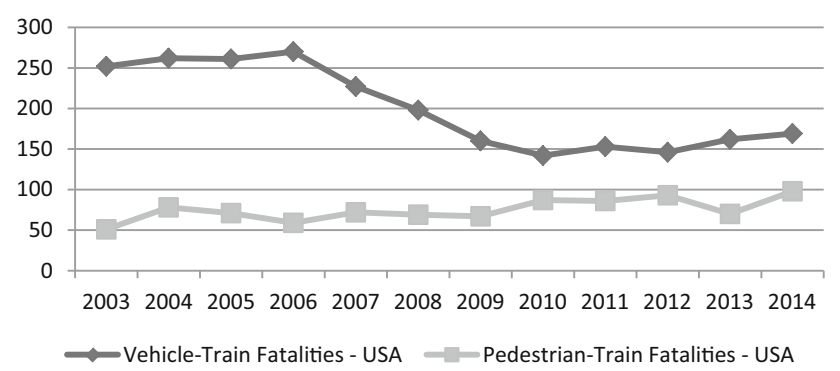

Fig. 1 Fatalities at highway-rail crossings in the United States. Source Federal Railroad Administration-Office of Safety Analysis

implementing adequate safety treatments arises from the fact that, in addition to pedestrians, pedestrian crossings serve other types of non-motorized users including pedestrians on skateboards, rollerblades, and equestrians, as well as cyclists and wheelchair users-although cyclists may mostly travel on the main highway as opposed to pedestrians and wheelchair users on the sidewalk.

A large array of treatments has been applied in different rail grade crossing environments to improve the safety of nonmotorized users, but their effectiveness remains difficult to assess [26]. This paper will highlight thematic areas related to pedestrian safety at rail grade crossings that are primed for further research and policy intervention. The presentation will synthesize literature findings and discussions with expert professionals in the public and private sectors. The objective of the paper is to offer an informed and focused discussion for researchers and practitioners involved with safety at rail grade crossings mainly in the United States.

\section{Literature Review}

In this paper, the terms 'pedestrian,' 'non-motorists,' and 'non-motorized users' will be used interchangeably to indicate crossing users who utilize pedestrian approaches to rail grade crossings. Such users include (obviously) pedestrians, pedestrians pushing a stroller, cyclists (either on bike or off their bike), and users on rollerblades, on wheelchair, skateboards, or even equestrians using an exclusive pedestrian approach to a rail grade crossing or the attached sidewalks of a rail-highway grade crossing.

The literature findings will discuss issues with warning devices, accessible non-motorist signals, engineering, education and enforcement, engineering standards and guidelines, intelligent grade crossings, and cost considerations. Such issues have received considerable attention and remain central in the discussion of pedestrian safety but, to our knowledge, have never been presented in a systematic manner. It would be worth noting that other important relevant issues not frequently found in the literature but identified in interviews with experts are presented in the second half of the paper.

\subsection{Warning Devices}

In an effort to "foster the exchange of information among and experiences among transportation agencies and organizations that are involved with pedestrian crossings of railroad tracks," the Federal Railroad Administration (FRA) compiled a report [37] on deployed pedestrian safety devices at grade crossings that are not included in the Manual on Uniform Traffic Control Devices (MUTCD). The report discusses both active and passive devices. Active devices change their appearance or position as soon as they receive a signal that a train is approaching from a train detection system. Passive devices do not change their appearance or position.

Examples of active devices discussed in the report include audible/visual devices, such as low-rise flashing pedestrian signals and multi-use path flashing light signals; short gate arms; and second train coming electronic warning signs. Examples of passive devices include highly reflective passive warning signs and channelizing devices, such as different types of fencing, swing gates, and zigzag or Z-gates. According to the report, various factors that should be examined during device selection include (a) collision experience, if any, at the crossing, as it involves pedestrians; (b) pedestrian volumes and peak flows, if any; (c) train speeds, numbers of trains, and railroad traffic patterns, if any; (d) sight distance that is available to pedestrians approaching the crossing; and (e) skew angle, if any, of the crossing relative to the railroad tracks.

A study evaluated the (preliminary) effects on pedestrian behavior of the installation of a second train warning trainactivated signal at a highway-rail crossing near the Vernon Avenue Station on the Los Angeles County Metropolitan Transportation Authority's Metro Blue light rail transit line [19]. The pedestrian sidewalk crossed two light rail transit (LRT) tracks and two freight rail tracks. Two measures of pedestrian behavior were examined: (a) the number of pedestrians entering the track area at $15 \mathrm{~s}$ or less before a train entered the crossing and (b) the number of pedestrians entering the track area at $6 \mathrm{~s}$ or less before a train entered the crossing with the flashers activated, a much riskier behavior. The study compared pedestrian behavior before and after installation and found that the installation of the signal reduced the incidence of risky pedestrian behavior by $14 \%$ on the first benchmark and $32 \%$ on the second one.

\subsection{Accessible Non-motorist Signals}

Accessible pedestrian signals (APS) are devices that communicate information about pedestrian timing in non- 
visual formats such as audible tones, verbal messages, and/ or vibrating surfaces (MUTCD, Section 4A.01) [36]. According to a synthesis on best practices [ [3], available at http://www.apsguide.org/], newer types of APS available can provide information to pedestrians about the existence and location of the pushbutton using audible tones; the onset of the walk interval using a vibrotactile indication; the direction of the crosswalk and location of the destination curb using different audible tones for north/south and east/west directions; the clearance interval using audible tones; intersection geometry through maps, diagrams, or speech; intersection street names in Braille, raised print, or speech; and intersection signalization using a pushbutton information message.

A description of these features is given in a series of reports produced by Project 3-62, "Guidelines for Accessible Pedestrian Signals of the National Cooperative Highway Research Program" [13-15]. Additional published guidelines are provided by the U.S. Architectural and Transportation Barriers Compliance Board [35].

APS at rail grade crossings may assist disabled pedestrians with making better judgments in regard to safely crossing the tracks at rail grade crossings. However, research about APS use in such environments is limited. Indeed Korve Engineering [20] found only limited research testing APS under field conditions in LRT environments and no additional research other than Blasch [4] comparing the effectiveness of different APS in normal traffic conditions. The study found there was a significant difference regarding their utility to provide a line of direction for street crossing, but no significant differences in regard to confidence and comfort of the user.

In addition, in the United Kingdom, Delmonte and Tong [9] conducted a comprehensive analysis to identify solutions for improving safety and accessibility at grade crossings for disabled pedestrians. More specifically, the study conducted discussion groups with disabled pedestrians, scored and ranked potential solutions, and developed an industry-approved set of solutions. The most promising solutions were grouped to create an 'ideal' accessible grade crossing. However, these solutions have not been field tested yet.

\subsection{Engineering, Education, and Enforcement}

Under the Rail Safety Improvement Act of 2008 (P.L. No. 110-432), the U.S. Department of Transportation has developed model railroad trespassing, vandalism, and highway-rail grade crossing warning device violation prevention strategies to assist State and local governments, and railroads. These strategies fall under three broad categories: (1) expanding educational outreach, (2) energizing enforcement, and (3) fostering engineering and sight improvements. Educational outreach involves public awareness programs helping non-motorists to safely navigate grade crossings. Consistent enforcement of traffic safety laws by State or local police and a sustained effort by the courts to impose penalties on violators discourage and deter non-motorists from making poor decisions at grade crossings. A recent report has published the latest compilation of state laws and regulations affecting highway-rail grade crossings [17]. Moreover, engineering improvements greatly reduce or prevent the potential for non-motorist-train collisions [38]. Finally, Fitzpatrick et al. [10] presents additional discussion about engineering treatments for light rail, commuter rail, and streetcar rail services.

The Illinois Commerce Commission (ICC), and the FRA initiated the Public Education and Enforcement Research Study (PEERS) to measure the before and after change in the public's adherence to traffic safety laws [33]. The study demonstrated a reduction in crossing violations and a dramatic reduction in the most dangerous pedestrian behavior. Moreover, Khattak and Luo [18] found there is a need for pedestrian and bicyclist outreach and education, especially for children 8 years old or younger. In addition, Lobb [25] suggested that lessons learned about behavior and consequences from cognitive psychology may apply to pedestrian safety at rail grade crossings.

\subsection{Engineering Standards and Guidelines}

The Federal Highway Administration's (FHWA's) Railroad-Highway Grade Crossing Handbook [27] provides guidance about pedestrian crossings. Additional guidance is provided by the MUTCD (Part 8) [36], American Railway Engineering and Maintenance of Way Association (AREMA) Communications \& Signal Manual [2], and Code of Federal Regulations 49 (Part 234). In addition, the FHWA's Handbook [27] identifies pedestrian crossing treatments and provides recommendations for flashing light signals, second train coming signals, dynamic envelope markings, pedestrian automatic gates, swing gates, bedstead (maze) barriers, z-crossing channelization, and combined pedestrian treatments.

Different standards apply to at-grade crossings of LRT. LRT has at least five different categories of operational alignments all of which have criteria for the type of warning systems needed at intersections based on the maximum operating speeds. Usually at speeds under 35 mph, LRTs use the existing street traffic signal controls in conjunction with priority and preemption controls [23]. At speeds above $35 \mathrm{mph}$, Active Warning Railroad systems are used in conjunction with adjacent traffic signal controls [21]. Additional guidelines for improving pedestrian and motorist safety along LRT alignments are reported in [8]. 
In California, CalTrain developed their own design criteria regarding grade crossings and began implementing them in 1999 [6]. These standard practices utilize active warning devices similar to those at vehicular crossings: signal equipment modified from that of vehicular crossing, crossing gate arm, and a crossing configuration which channels pedestrians. Different design criteria apply for pedestrian crossings in general regarding warning time, center fence, warning devices, safety buffer zone, warning assemblies, gate recovery, as well as pedestrian crossings at stations, at stations and roadway, and crossings between roadway crossings.

In addition, also in California, the SCRRA (aka Metrolink) Highway-Rail Grade Crossings Recommended Design Practices and Standards Manual [31] is a comprehensive single document that incorporates current and applicable highway-rail and pedestrian-rail grade crossing design standards and recommended design practices. Regarding pedestrian-rail grade crossings, the manual finds that pedestrian treatments work well with proper channelization and signs, as well as sidewalks on either side of tracks and/or through the track area. Moreover, pavement striping continued across the track portion of roadway is a good visual and effective. In addition, it is important to add extra pedestrian treatments near stations for riders running to catch trains. Finally, the manual provides a decision tree to determine the designs of pedestrian-rail grade crossings and appropriate warning treatments.

The American Public Transportation Association (APTA) provides guidance for rail transit systems for selecting, installing, and operating highway-rail transit grade crossing warning systems and includes minimum requirements for highway-rail grade crossing warning devices, highway traffic signs, and other highway traffic control appliances [1]. Particular recommendations are made for pedestrians at rail grade crossings.

The California Public Utilities Commission (CPUC) has published extensive design guidelines for pedestrian-rail crossings within the state of California [5]. Their review of design considerations and installations includes recommendations for swing gates, detectable warnings, and pedestrian gates, flashing light signal assemblies, signage, crossing surfaces, channelization design, and other treatments. Signage must conform to the state MUTCD. The report makes a particular reference to the Transportation Research Board's Transit Cooperative Research Program (TCRP) Report 69 Section 3.8 .3 [21] which provides a decision tree as a tool to determine appropriate pedestrianrail at-grade crossing treatments. The tool has been adopted by TriMet in Portland, Oregon but otherwise has not been validated by research (private communication with Brent Ogden, one of the co-authors of the study, 11/17/2011). In addition, a risk-scoring methodology to evaluate safety factors at station pedestrian crossings is in use in the United Kingdom [34].

A risk assessment methodology for pedestrian grade crossings is part of the Australian Level Crossing Assessment Model (ALCAM) still under development [11, 32]. The model is an assessment tool used to identify key potential risks at level crossings and to assist in the prioritization of railway level crossings according to their comparative safety risk. ALCAM uses a scoring algorithm which considers each level crossing's physical properties (characteristics and controls) including consideration of the related common human behaviors, to provide each level crossing with a "Likelihood Factor" score. This score is then multiplied by the level crossings "Exposure" score (a factor taking into account the volumes of Vehicles/Pedestrians and Trains) and finally multiplied by the Consequence score (which is set to be one for pedestrians) to give the ALCAM Risk Score.

The ALCAM model is designed to apply for both active and passive grade crossings, whereas the Risk Assessment of Accident and Incident at Level crossings (RAAILc) model can be used for predicting accidents at passive level crossings only. A review by Little [22] has categorized ALCAM under a simple weighted factor, and RAAILc as a statistically driven approach. Note that the ALCAM model is different from the All Level Crossings Risk Model (ALCRM) that was developed in the United Kingdom and was categorized as a complex weighted factor model in that review. Interestingly, Little, in the same review, found only four operational models that take into account the number of pedestrians using the crossing. Newer approaches based on simulation methods such as Petri nets are still developing [16].

\subsection{Intelligent Grade Crossings}

Interesting new developments in the area of Cooperative Intelligent Transportation Systems (ITS) may bring to bear applications that could dramatically affect safety for nonmotorized users in grade crossings in the not so distant future. Vehicle-to-vehicle (V2V), vehicle-to-infrastructure (V2I), and vehicle-to-consumer devices (V2D) are being developed to deliver more safety mobility benefits. Pedestrians and non-motorized users, in general, at rail grade crossings will be able to receive personalized advance warning of incoming trains in time to avoid injuries and fatalities.

\subsection{Cost Considerations}

Cost estimates and/or actual costs of non-motorist warning systems at rail grade crossings already installed are not generally available as discussed later in the paper. 
Moreover, costs can vary widely with the additional infrastructure needed in support of the treatment. For example, pedestrian automatic gates, pedestrian automatic gates with horizontal hanging bar, and pedestrian swing gates are thought of as medium-cost safety treatments with their cost generally estimated as being between $\$ 10,000$ and $\$ 100,000$ [10]. Even the total expense for low-cost solutions such as fencing estimated between \$130/linear ft. and $\$ 334 /$ linear $\mathrm{ft}$. can be highly variable as fencing may only be for a few linear feet or could be for more than a mile [10].

Additional information on cost estimates of pedestrian safety treatments in Illinois and other states in the United States is reported elsewhere [26]. We now discuss some of the findings from earlier studies.

The cost breakdown (2000 U.S. dollars) of the "Second Train Coming" warning sign demonstration (TRB, 2001) included (a) $\$ 15,000$ for the "Second Train Coming" sign; (b) $\$ 80,000$ for the sign installation including track circuit modification and camera equipment; (c) $\$ 35,000$ for project management and engineering; and (d) $\$ 70,000$ for project evaluation.

Cost figures provided by SafeTran Systems [28] about the cost of active warning systems provide a component breakdown showing, among other things, that for a fully redundant system, installation (labor) is one of the largest cost components, ranging from 25 to $35 \%$ of the total system cost (for Class I railroads). Train detection, on the other hand, may only comprise $20-25 \%$ of the total costand train detection is where most people think the economies are to be achieved.

More recently, Roop et al. [30] argue that likely candidate technologies that can reduce active warning costs at highway-rail crossings are those with significantly lower installation costs. In a fully redundant system, installation is one of the largest cost items of systems now in use, ranging from 25 to $35 \%$ of the total system cost.

\subsection{Conclusions from the Literature Review Synthesis}

It is evident from the previous literature review that there is a considerable body of research that has studied several dimensions of the problem regarding improving pedestrian safety at rail grade crossings. These research efforts have investigated issues with warning devices, accessible nonmotorist signals, engineering, education and enforcement strategies, engineering standards and guidelines, intelligent transportation technologies, and treatment costs. To the extent that such issues would need to be addressed whenever new safety treatments are being planned, designed, implemented, and evaluated, it is also clear that very few, if any, studies have delved into these issues in a holistic manner. This is probably due to the lack of scope, resources, or, more likely, methodologies capable of untangling interconnections among these matters. Indeed very few existing methodologies allow for assessing tradeoffs among those factors during the selection process, and the potential of newer approaches is not well understood.

\section{Interviews with Expert Professionals}

We conducted telephone interviews of experts in rail crossing safety from both the public and private sectors using structured questionnaires that were based on findings from the literature. The experts were selected based on recommendations from a technical review panel overseeing the study this paper is based on [26]. All experts had a long-more than 20 years-involvement with railroad operations safety and rail grade crossings safety, in particular, and have been members of several TRB and AREMA committees. Note that academic (Institutional Research Board) protocol prohibits us from naming those interviewees.

In the public sector, we spoke with two USDOT and 25 experts at state Departments of Transportation and public utility commissions with jurisdiction over transportation and rail crossings. At the state level in alphabetical order, we spoke with experts from Alabama, California, Colorado, District of Columbia, Florida, Illinois, Iowa, Louisiana, Maryland, Michigan, Minnesota, New Jersey, North Carolina, North Dakota, Oregon, Texas, Utah, West Virginia, Wisconsin, and Wyoming. At the federal level, we spoke with experts at the FRA and at the FHWA. Finally, in the private sector, we spoke with eight professionals who have had a long tenure consulting on railroad level crossing safety.

The purpose of the interviews was to obtain information about (1) additional relevant literature that could not be located in the literature search discussed in the previous section (e.g., internal studies, consultant reports); (2) agency experiences with planning, implementation, and evaluation of warning devices under study; (3) cost estimates and/or actual costs of such warning systems; and (4) policies for use of warning signs for non-motorized users at grade crossings. Each telephone interview was scheduled a week or longer in advance and lasted between 45 and $65 \mathrm{~min}$. The following questions were asked:

- What types of non-motorist safety treatments have you installed at rail grade crossings?

- What types of APS have you installed?

- What information do you have on cost estimates and/or actual costs of the warning systems you have already installed? 
- How do you evaluate the cost effectiveness of such safety treatments?

- What criteria are you using for the selection of warning devices for deployment?

- How do you prioritize/make trade-offs between these factors during the selection process?

- What engineering standards and guidelines do you apply to such crossings?

- What are your educational outreach activities (e.g., public awareness programs, partnerships with other organizations, etc.). How effective are they?

- What are your enforcement initiatives (e.g., police, courts). How effective are they?

- What is your overall budget for safety at grade crossings? For pedestrian safety?

- Can you provide a percentage cost breakdown among engineering, education, and enforcement activities?

- What funding sources do you make use of to promote pedestrian safety at rail crossings?

- What are your policies/warrants/standards for using warning signs for non-motorized users at rail grade crossings (e.g., minimum warning times at/near to/far from commuter stations, design/installation/operational guidelines, etc.)?

- What state and local regulations in addition to federal regulations apply to non-motorized users at rail grade crossings in your area?

These questions served as a means to steering each narrative interview to elicit a valid account of participant perspectives with minimal interviewer influence. As a first step in the analysis of the interviews, each interview required 6-8 $\mathrm{h}$ for word-by-word transcription. Subsequently and for each transcribed interview, a text reduction into summary sentences and, eventually, thematic areas was conducted. This narrative interview analysis subjectively identified focal points as discussed in the next section. In this regard, each interview participant contributed insights into multiple themes but a more formal quantitative analysis was not attempted.

More details about individual interviews can be found elsewhere [26]. Overall, interview participants did not provide additional literature compared to the information discussed in the previous section. Therefore, the cited literature in the next section indicates that a particular argument made by interviewee(s) is in agreement with prior published work.

\section{Focus Areas for Improving Pedestrian Safety}

The discussion below will focus on several general themes that emerged from these interviews, which in turn, seem to raise a number of issues regarding safety at pedestrian-rail highway grade crossings. Some of the issues have been discussed, mainly, in relation to motorist safety at rail grade crossings [7, 27]. However, none of these issues has been thoroughly discussed in relation to pedestrian safety at such locations.

\subsection{Prioritization of Safety Upgrades}

All interview participants agreed that safety upgrades are usually prioritized based on a diagnostic review process that examines a number of criteria (e.g., number of tracks, engineering design, number of trains, train speed, etc.), but decisions are usually based on a consensus among relevant stakeholders representative of all groups having responsibility for the safe operation of crossings rather on a formal cost-effectiveness methodology. However, due to funding constraints, safety upgrades at dedicated pedestrian crossings are not prioritized as highly as those at rail-highway grade crossings unless these two types of crossings are adjacent to each other (e.g., adjacent sidewalks on one or either side of a rail-highway crossing extending to the other side of the tracks).

\subsection{Engineering Standards}

Based on the interviews, states with substantial passenger, commuter, and freight rail operations are leading the effort to develop guidelines and engineering standards for safety improvements. Moreover, it is likely that pedestrian safety at rail grade crossings will benefit in the longer term by the increasing consistency in standards for warning devices and treatments among organizations responsible for this task. As an example of standards consistency, the definition of advance preemption in MUTCD looks the same as the one in AREMA and Institute of Transportation Engineers (ITE) documents as well as in APTA standards.

The requirement for extra warning time for pedestrians and motorists in grade crossings of high-speed rail operations is emerging as an additional issue for safety upgrades at such crossings. Currently, the typical warning time at crossings where pedestrians may be present is between 20 and $30 \mathrm{~s}$ for conventional speed trains. In an environment with 110 mile an hour trains, there would be a need to provide confirmation signals to the train crew and the onboard computer that the crossing is clear likely requiring a warning time of at least $80 \mathrm{~s}$. The question about how pedestrians will react to such extended warning times at pedestrian crossings remains to be determined. This is because currently most of the warning time is built into the time that the train occupies the crossing. When high-speed trains begin to operate, most of the warning time is going to be built into the time for the train approaching the crossing. Therefore, there would be an extended warning time where 
the crossing remains unoccupied while a high-speed train cannot even be seen on the horizon. This situation will require "reeducation" of the public, especially in areas where crossings are very near to each other.

\subsection{Reliability of Cost Estimates}

The interviews revealed that cost estimates and/or actual costs of the warning systems already installed, unless for dedicated pedestrian crossings, are not generally available despite federal requirements, under the Safe, Accountable, Flexible, Efficient Transportation Equity Act: A Legacy for Users (SAFETEA-LU) program (formerly known as "Section 130"), to the contrary. This is probably due to the fact that such funds are usually absorbed into much larger projects (e.g., grade separation). Moreover, a cost breakdown for design, installation, component maintenance, and operating costs is rarely finalized considering the actual costs keep changing as they move from the planning stage, to the design stage, to the design and build stage. Additional reasons are presented elsewhere [30].

Such difficulties, in addition to lacking dedicated funding for cost-effectiveness studies, result in the general lack of cost-effectiveness information of pedestrian safety treatments. On the other hand, given that the number of fatalities at grade crossings is relatively low, it would be very difficult to assign a cost-effectiveness value to a particular treatment. In any case, cost oversight from state departments of transportation may be needed to effectively manage targeted funding for grade crossings safety improvements.

\subsection{Funding Availability}

All interview participants agreed that the vast majority of funding available for safety improvements is programmed for rail-highway crossings, and very rarely exclusively for dedicated pedestrian grade crossings. Some interviewees opined that it would be critical that Section 130 funding remain exclusive to railroad safety and not rolled back with other highway funds. Continuing this source of support would help maintain the level of expertise for rail safety at the FRA as well at state departments of transportation.

\subsection{Selection Criteria}

Based on the interviews, a number of criteria are used for the selection of warning devices for deployment at pedestrian-rail grade crossings including pedestrians collision experience at the crossing, frequency of inclement weather, pedestrian volumes and peak flows, train speeds, numbers of trains, and railroad traffic patterns, surrounding landuses, sight distance for pedestrians approaching the crossing, skew angle of the crossing relative to the railroad tracks, multiple tracks, vicinity to a commuter station, and installation/maintenance costs. Furthermore, to discourage trespassers at or in the vicinity of grade crossings, communities apply fencing, landscaping, prohibitive signs, video monitoring, education/outreach, and enforcement.

However, very few existing methodologies allow for assessing trade-offs between these factors during the selection process (e.g., similar in functionality to the FRA's Accident Prediction Formula), and the potential of newer approaches is not well understood. Despite the absence of a formal cost-effectiveness evaluation process, in practice the process is realized as a consensus-building exercise among the diagnostic team members.

A way to formalize this process would be to ask, first, whether the particular crossing under consideration may be closed or consolidated with neighboring crossings. This is an important decision because a crossing closure may be helpful to limiting the number of automobile exposures but is nearly ineffective in limiting pedestrian exposures. Unless additional treatments to prevent pedestrian use are done, pedestrians would likely continue to cross where they always have, except now as trespassers. Once such considerations have been resolved, then the process would continue by examining the cost of various safety treatment options available versus the expected benefits.

\subsection{Lack of Accessible Pedestrian Signals}

All interview participants agreed that the lack of APS at pedestrian-rail grade crossings is mainly due to the shortage of dedicated funding for such crossings. Such signal treatments need not convey the type of messages needed in regular intersection street crossings with more complicated traffic patterns. Occasionally, there are situations in grade crossing improvement projects where certain options are not available. For example, in the absence of adequate right of way, it usually becomes impossible to produce accessible sidewalks of the proper width in compliance with the Americans with Disabilities Act (ADA) standards. Another reason for the infrequent use of accessible signals (other than detectable strips and detectable yellow tiles just ahead of the pedestrian gates) at rail grade crossings is the lack of standardization among manufacturers.

\subsection{Education and Enforcement Campaigns}

Interviewees believe that strong local advocacy is probably the most important factor other than adequate funding availability behind effective education, outreach, and enforcement safety campaigns at pedestrian-rail grade crossings. Moreover, such campaigns should continue unmitigated with additional service improvements in 
different geographic locations. Furthermore, campaigns for light rail grade crossing safety can be relatively more effective with the active participation of a transit agency and a captive local audience exposed to the frequency of transit operations.

\subsection{Risk Management}

The interviews revealed that the states did not have a consistent approach for managing the risk at pedestrian-rail grade crossings that could assure (a) the uniformity and continuity of data collection programs and administration of related databases on all such crossings; (b) the analysis of risks at such crossings; (c) the prioritization of crossing upgrades; (d) the introduction of suitable risk controls; and (e) the assessment of cost effectiveness of such measures. Perhaps the FRA could promote a national campaign to this end with all states committing to the approach.

Interview experts seem to agree on a five-point program of risk management (affectionately called the five 'Es'-_Engineering,' 'Education,' 'Enforcement,' 'Enabling,' and 'Evaluation') to increase safety at pedestrian (and vehicular) rail grade crossings. Note that the first three 'Es' have been key underlying principles of Operation Lifesaver in the USA. 'Enabling' was added during the formation in Britain of the National Level Crossing Safety Group (NLXSG) in 2002, and is concerned with providing resources, people, and systems to facilitate progress with improving level crossing safety [24]. 'Evaluation' was added more recently, and has become of particular interest in Europe where attention is being paid to developing common reporting methods for level crossings (i.e., types of crossings, numbers, and risk measurement), and being able to measure the effectiveness of programs. Little [24] defined these five 'Es' as follows:

- Enabling: The provision of resources through people, procedures, and systems to allow the other 'Es' to be effective.

- Education: Increasing public awareness of the dangers of crossings and educating pedestrians, road vehicle drivers, and other users how to use them correctly.

- Engineering: The protection fitted to level crossings through lights, horns, barriers, telephones, and signs together with research into innovative means of increasing safety.

- Enforcement: The use of laws to prosecute those who endanger themselves or others by misuse of crossings.

- Evaluation: The idea as envisaged by the NLXSG is to encourage organizations to set a baseline before embarking on new initiatives so that the before and after can be properly compared.
Based on the interviews, it appears that the majority of the research focusing on mitigating the risk for non-motorized users at rail grade crossings has focused on the grade crossing risk as a potential cause of train accidents rather than the individual risk to such users. However, the level of risk to which an individual is exposed is a key consideration in the safety management process, but is not explicitly part of the criteria applied to deciding about whether or not to implement an action to improve safety. This is in agreement with the literature [29].

\subsection{Public and Private Stakeholder Responsibilities}

Interviewees believe that determining the most suitable mix of safety upgrades at pedestrian crossings is a challenging issue complicated by the fact that regulatory authorities make the selection, while the operating railroads are responsible for the installation and life-cycle costs. The public authority is interested to select the most robust technology available to maximize the public investment in the long run. On the other hand, the private railroad is looking to minimize the life-cycle costs of a technology that is likely to become obsolete before the end of its life and thus expensive to maintain.

\subsection{Quiet Zones}

Some interviewees seem to believe that non-motorized users at grade crossings within quite zones may not receive safety benefits comparable to motorists. This is because, and this is only a conjecture at this point, supplemental safety measures (SSMs), such as gates and flashing lights are mostly focusing on motorists, while alternative safety measures (e.g., non-engineering elements such as public awareness campaigns or photo enforcement technology to increase driver and pedestrian awareness at grade crossings) may not be necessary for the establishment of a quiet zones if adequate SSMs have been installed. As a result, distracted non-motorists may not be sufficiently alerted to an incoming train, especially when a second train is coming from the opposite direction.

\subsection{Conclusions from Interviews with Experts}

The discussion with the experts in this section seems to highlight a number of areas primed for further research and policy intervention. First, as consistency of engineering standards improves, it would be important to monitor the impact on pedestrian safety. Second, high-speed passenger rail service will require re-education of pedestrian users regarding safety impacts at or in the vicinity of or away from grade crossings. Third, it is increasingly important to better track the programming and the expenditure for safety 
upgrades at grade crossings. Fourth, there is a need to develop a cost-effectiveness evaluation process to facilitate the activities of a diagnostic team. Fifth, it is important to address the needs of users with disabilities at grade crossings to better manage the risk for catastrophic incidents. Sixth, continuation of adequate funding for strong local advocacy toward education and enforcement activities is critical to pedestrian safety. Finally, the development of an appropriate risk management approach would better support the planning, programming, and implementation of safety upgrades at pedestrian grade crossings.

\section{Conclusions}

The number of incidents between trains and non-motorist users at rail grade crossings has remained relatively unchanged in recent years despite a noticeable parallel reduction in the number of collisions between vehicles and trains at rail-highway grade crossings. However, the reasons for such an outcome disparity are not well understood. This paper identified several dimensions of the problem by, first, examining the literature for pertinent research on pedestrian safety at rail grade crossings and categorizing the findings into thematic areas. The two primary findings from the literature review can be summarized as follows:

1. There is a wide variety of MUTCD compliant signs and devices used to warn pedestrians of the presence of a crossing, as well as the approach of a train. There are also a large number of non-compliant MUTCD signs and devices utilized.

2. The effectiveness to reduce the risk of a collision between a pedestrian and a train of any particular sign or device is unknown. Few existing methodologies allow for assessing trade-offs among those factors during the selection process, and the potential of newer approaches is not well understood. In particular, there is no commonly accepted method to quantify the risk to pedestrian of being struck by a train at either a highway-rail crossing with pedestrian access, or a dedicated stand-alone pathway-rail crossing.

In the second half of the paper, we sought to complement the earlier findings by talking to experts in the public and private sectors and organizing their thoughts into additional thematic areas. The principal findings can be summarized as follows:

1. Safety upgrades at dedicated pedestrian crossings are not prioritized as highly as those at highway-rail grade crossings unless the two types of crossings are adjacent to each other (e.g., adjacent sidewalks on one or both sides of a highway-rail crossing extending to the other side of the tracks).

2. The vast majority of funding available for safety improvements is usually planned for rail-highway crossings; very rarely are these funds scheduled exclusively for dedicated pedestrian grade crossings.

3. States with substantial passenger, commuter, and freight rail operations are leading the effort to develop guidelines and engineering standards for safety improvements.

4. Cost estimates and/or actual costs of the warning systems already installed are not readily available.

5. Criteria for the selection of warning devices for deployment at pedestrian-railway grade crossings are used on a case-by-case basis, likely because of a lack of available methods to assess criteria trade-offs.

6. Strong local advocacy is the most important factor, other than adequate funding, behind effective education, outreach, and enforcement safety campaigns at pedestrian-rail grade crossings.

7. Education and enforcement campaigns must be sustained over time and place and use a variety of techniques to engage the user community. Campaigns for commuter and light rail grade crossing safety can be relatively more effective with the active participation of the transit agency and a captive local audience exposed to the frequency of transit operations.

8. There is no consistent approach for managing risk at pedestrian-rail grade crossings that could ensure (1) the uniformity and continuity of data collection programs and administration of related databases on all such crossings; (2) the analysis of risks at such crossings; (3) the prioritization of crossing upgrades; (4) the introduction of suitable risk controls; and (5) the assessment of cost effectiveness of such measures.

9. Non-motorized users at grade crossings within quiet zones may not receive safety warning comparable to motorists. As a result, distracted non-motorists, especially when traveling in groups, in such an environment may not be sufficiently alerted to an incoming train, especially when a second train is coming from the opposite direction.

10. It is likely that pedestrian safety at rail grade crossings will benefit in the longer term by the increasing consistency in standards for warning devices and treatments among organizations responsible for this task.

11. The requirement for extra warning time for pedestrians and motorists at grade crossings of high-speed rail operations is emerging as an additional issue for safety upgrades at such crossings. 
It should be noted that the focus of the discussion in this paper is on individuals who utilize legally authorized highway-rail crossings with pedestrian access, or legally authorized pathway-rail crossings. Individuals crossing railroad tracks at locations other than legally designated locations are trespassing upon private property. While trespassing is a major public safety issue, it is not the focus of this research.

We believe, however, that, within its scope, the paper will provide a solid basis for future research on the topic. Addressing each of these areas of concern would require a continuing commitment to education, engineering, enforcement, and evaluation efforts. This can be achieved by enabling organizations involved in all aspects of pedestrian safety at rail grade crossings to provide adequate resources through trained personnel, diagnostic procedures, and systems implementation.

Acknowledgments This paper is based on research conducted under the sponsorship of the Illinois Center for Transportation Grant: IDOT R27-96. Additional support has been provided by Grant: DTRT12-G-UTC18 from the U.S. Department of Transportation. The authors declare that they have no conflict of interest.

Open Access This article is distributed under the terms of the Creative Commons Attribution 4.0 International License (http://crea tivecommons.org/licenses/by/4.0/), which permits unrestricted use, distribution, and reproduction in any medium, provided you give appropriate credit to the original author(s) and the source, provide a link to the Creative Commons license, and indicate if changes were made.

\section{References}

1. American Public Transportation Association (2007) Standard for rail transit grade crossing warning system design criteria, installation and operation. Revision approved February 7, 2007. Report APTA RT-S-RGC-004-03

2. American Railway Engineering and Maintenance of Way Association (2010) Communications \& Signal Manual, vol 1, Sect 3

3. Barlow JM, Bentzen BL, Tabor L (2003) Accessible pedestrian signals: Synthesis and guide to best practice. National Cooperative Highway Research Program, Research Results Digest, July 2003-Number 278. Transportation Research Board, National Academy of Sciences, Washington, DC

4. Blasch B (1999) Effectiveness of accessible pedestrian signals. Final Report. Veterans Affairs Medical Center, Rehabilitation Research and Development Center, Atlanta

5. California Public Utilities Commission (2008) Pedestrian-rail crossings in California: a report compiling the designs and devices currently utilized at pedestrian-rail crossings within the state of California, May 2008

6. CalTrain (2007) Design criteria. April 15, 2007

7. Carroll AA, daSilva MP, Ngamdung T (2010) U.S. DOT Federal Railroad Administration's third research needs workshop on highway-rail grade crossing safety and trespass prevention: vol I-summary of results. U.S. Department of Transportation, Research and Innovative Technology Administration, John A. Volpe National Transportation Systems Center. Report Number DOT-VNTSC-FRA-10-02, January 2010
8. Cleghorn D, Clavelle A, Boone J, Masliah M, Levinson HS (2009) Improving pedestrian and motorist safety along light rail alignments. TCRP Report 137. Transportation Research Board, Washington, DC

9. Delmonte E, Tong S (2011) Improving safety and accessibility at level crossings for disabled pedestrians. Report Number T650. Rail Safety and Standards Board, London, February 2011

10. Fitzpatrick K, Warner J, Brewer MA, Bentzen BL, Barlow JM, Sperry B (2015) Guidebook on pedestrian crossings of public transit rail services. TCRP Report 175. Transportation Research Board, Washington, DC

11. Ford G, Heneker D (2004) The Australian level crossing assessment model. In: International rail safety conference, Perth 24-27 October, 2004, Queensland, Australia

12. Goldberg BA, Mootha RK, Lindsey RW (1998) Train accidents involving pedestrians, motor vehicles and motorcycles. Am J Orthop 27(4):315-320

13. Harkey DL, Carter DL, Barlow JM, Bentzen BL (2007) Accessible pedestrian signals: a guide to best practices. NCHRP WebOnly Document 117a. National Cooperative Highway Research Program, Transportation Research Board, Washington, DC

14. Harkey DL, Carter DL, Barlow JM, Bentzen BL, Myers L, Scott A (2007) Guidelines for accessible pedestrian signals. Final Report. NCHRP Web-Only Document 117b. National Cooperative Highway Research Program, Transportation Research Board, Washington, D.C

15. Harkey DL, Carter DL, Barlow JM, Bentzen BL (2009) Accessible pedestrian signals: A guide to best practices (workshop edition 2010). NCHRP Web-Only Document 150. National Cooperative Highway Research Program, Transportation Research Board, Washington, DC

16. Ishak SZ, Yue WL, Somenahalli S (2010) Level crossing modelling using petri nets approach and $\pi$-tool. Asian Transp Stud 1(2):107-121

17. Jennings LS (2009) Compilation of state laws and regulations affecting highway-rail grade crossings, 5th edn. Department of Transportation, Federal Railroad Administration, Washington, DC

18. Khattak A, Luo Z (2011) Pedestrian and bicyclist violations at highway-rail grade crossings. Transp Res Rec Board 2250:76-82

19. Khawani V (2001) "Second Train Coming" warning sign demonstration project. Transp Res Rec 1762:32-36

20. Korve Engineering (2007) Appendixes to TCRP RRD 84: audible signals for pedestrian safety in LRT environments. TCRP WebOnly Document 35. Transportation Research Board, Washington, DC

21. Korve HW, Ogden BD, Siques JT, Mansel DM, Richards HA, Gilbert S, Boni E, Butchko M, Stutts, JC, Hughes, RG (2001). Light rail service: pedestrian and vehicular safety. TCRP Report 69. Transportation Research Board, Washington, DC

22. Little AD (2007a) Use of risk models and risk assessments for level crossings by other railways. Final Report to Rail Safety and Standards Board. Rail Safety and Standards Board, London, March 2007

23. Korve HW, Farran JI, Mansel DM, Levinson HS, Chira-Chavala T, Ragland DR (1996) Integration of light rail transit into city streets. TCRP Report 17. Transportation Research Board, Washington, DC

24. Little AD (2007b) Analysis of research ideas from recent international level crossing conferences. Report Number T527 to Rail Safety and Standards Board. Cambridge, June 2007

25. Lobb B (2006) Trespassing on the tracks: a review of railway pedestrian safety research. J Saf Res 37(4):359-365

26. Metaxatos P, Sriraj PS (2013). Pedestrian/bicyclist warning devices and signs at highway-rail and pathway-rail grade crossings. Research Report FHWA-ICT-13-013. Illinois Center for Transportation, April 2013 
27. Ogden BD (2007) Railroad-highway grade crossing handbookrevised second edition 2007. Report No. FHWA-SA-07-010. Office of Safety Design Federal Highway Administration

28. Petit B (2001) Breakdown of current highway-rail grade crossing system costs. In: Proceedings of the national highway-rail grade crossing safety conference, Texas Transportation Institute, Dallas, TX

29. Rail Safety and Standards Board (2010) Road-rail interface special topic report, London, April 2010

30. Roop SS, Roco CE, Olson LE, Zimmer RA (2005) An analysis of low-cost active warning devices for highway-rail grade crossings. NCHRP Project No. HR 3-76B, Task Order 4. Final Report, March 2005

31. SCRRA (2009) SCRRA highway-rail grade crossings recommended design practices and standards manual, 30 Jun 2009

32. Spicer T (2007) Implementing the Australian level crossing assessment model (ALCAM) in Victoria. In: Proceeding of the 30th Australasian Transport Research Forum (ATRF 2007), Langham Hotel, Melbourne, 25-27 Sep 2007

33. Sposato S, Bien-Aime P Chaudhary M (2006) Public Education and Enforcement Research Study. Report DOT-VNTSC-FRA-06-
03. U.S. Department of Transportation, Research and Innovative Technology Administration, John A. Volpe National Transportation Systems Center, Cambridge

34. U.K. Department for Transport-Rail Accident Investigation Branch (2006) Rail accident report-investigation into station pedestrian crossings. Report 23/2006, December 2006

35. U.S. Architectural and Transportation Barriers Compliance Board (2005) Notice of availability of draft public rights-of-way accessibility guidelines. Washington, DC

36. U.S. Department of Transportation, Federal Highway Administration (2009) Manual on uniform traffic control devices

37. U.S. Department of Transportation, Federal Railroad Administration (2008) A compilation of pedestrian safety devices in use at grade crossings. Office of Safety, Federal Railroad Administration, January 2008

38. U.S. Department of Transportation, Federal Railroad Administration (2010) Railroad trespassing, vandalism, and highway-rail grade crossing warning device violation prevention strategies. Office of Railroad Safety, December 2010 